\title{
Clathrate Hydrates of Isopentane + Carbon Dioxide and Isopentane + Methane: Experimental Measurements of Dissociation Conditions
}

\author{
A.H. Mohammadi and D. Richon \\ MINES ParisTech, CEP/TEP - Centre Énergétique et Procédés, 35 rue Saint-Honoré, 77305 Fontainebleau - France \\ e-mail: amir-hossein.mohammadi@ensmp.fr - dominique.richon@ensmp.fr
}

\begin{abstract}
Résumé - Hydrates (clathrates) d'isopentane + dioxyde de carbone et d'isopentane + méthane : Déterminations expérimentales des conditions de dissociation - Des données expérimentales de dissociation d'hydrates d'isopentane + dioxyde de carbone et d'isopentane + méthane sont respectivement présentées ici dans les gammes de température (273.5-282.4) et (275.5-285.7) K. Ces valeurs expérimentales ont été générées en utilisant une méthode isochore de recherche d'une discontinuité de pression. La fiabilité de cette méthode est examinée grâce à la production de données nouvelles pour la dissociation des hydrates de méthane + isopentane et à leur comparaison à des données expérimentales disponibles dans la littérature. L'accord tout à fait acceptable permet de garantir la fiabilité de la méthode expérimentale utilisée. Les valeurs expérimentales de tous les systèmes mesurés sont finalement comparées aux données expérimentales correspondantes de la littérature, obtenues toutefois en l'absence d'isopentane, et ce afin de quantifier ses effets promoteurs de formation d'hydrates.
\end{abstract}

\footnotetext{
Abstract - Clathrate Hydrates of Isopentane + Carbon Dioxide and Isopentane + Methane: Experimental Measurements of Dissociation Conditions - In this work, experimental dissociation data for clathrate hydrates of isopentane + carbon dioxide and isopentane + methane are reported in the temperature ranges of (273.5-282.4) and (275.5-285.7) $\mathrm{K}$, respectively. The experimental data were generated using an isochoric pressure-search method. The reliability of this method is examined by generating new dissociation data for clathrate hydrates of isopentane + methane and comparing them with the experimental data reported in the literature. The acceptable agreement demonstrates the reliability of the experimental method used in this work. The experimental data for all measured systems are finally compared with the corresponding experimental data in the absence of isopentane reported in the literature to identify its promotion effects.
} 


\section{INTRODUCTION}

Petroleum reservoir fluids are normally produced with water. Formation of gas hydrates is a serious problem that can cause equipment blockage and operational, safety and economical problems. Gas hydrates, or clathrate hydrates, are a group of nonstoichiometric, icelike crystalline compounds formed through a combination of water and suitably sized "guest" molecule(s) under low-temperatures and elevated pressures [1]. In clathrate hydrates, water molecules form hydrogenbonded cagelike structures, encapsulating the guest molecules, which generally consist of low molecular diameter gases and organic compounds [1]. The common gas hydrate structures are those of structure I $(s I)$, structure II $(s I I)$ and structure $\mathrm{H}(s H)$, where each structure is composed of a certain number of cavities formed by water molecules [1]. For a molecule to enter a cavity, its size should be smaller than a certain value [1]. Large molecule guests which can enter only a limited number of large cavities require small "help gas" molecules, like methane, etc., to mainly fill some smaller cavities sufficiently to stabilize hydrate crystals [1]. Petroleum reservoir fluids components are typically characterized up to, and including, $\mathrm{C}_{5}, \mathrm{C}_{6}$ and heavier components are normally lumped into hydrocarbon groups, i.e., no additional information on Heavy Hydrate Formers (HHF) is generally available. Therefore, the effect of HHFs on hydrate stability zone cannot be taken into account, while it is believed that some of these HHFs can have significant effects on gas hydrate phase equilibria of petroleum reservoir fluids [1]. Many efforts have been made to measure hydrate phase equilibrium boundaries of these HHFs. In most of cases, methane was used as help gas [1]. A comprehensive literature review for these HHFs is given by Sloan and Koh [1]. It has been reported that isopentane (2-methyl butane) can form clathrate hydrates with a help gas like methane [1]. However, the information on other help gases is limited.

In this work, dissociation data for clathrate hydrates of isopentane + carbon dioxide and isopentane + methane are reported in the temperature ranges of (273.5-282.4) and (275.5-285.7), respectively. The experimental data were generated using an isochoric pressure-search method [2-5]. As sufficient hydrate dissociation data for the methane + isopentane + water system have already been reported in the literature $[1,6,7]$, therefore, we first generated and report experimental data for the latter system and compare them with the experimental data reported in the literature $[1,6,7]$ to demonstrate the reliability of the experimental method [2-5] used in our work. We then report dissociation data for isopentane clathrate hydrates with carbon dioxide as help gas. The experimental data for all the studied systems are finally compared with some selected experimental data from the literature in the absence of isopentane [8-10] to identify its promotion effects.

\section{EXPERIMENTAL SECTION}

\subsection{Chemicals}

Table 1 reports the purities and suppliers of the chemicals used in this work.

TABLE 1

Purities and suppliers of chemicals*

\begin{tabular}{c|c|c}
\hline Chemical & Supplier & Purity \\
\hline Methane & Messer Griesheim & $99.995($ mole \%) \\
Carbon dioxide & Air Liquide & $99.995($ mole \%) \\
Isopentane & Sigma-Aldrich & $99+\%$ \\
\hline
\end{tabular}

* Deionized water was used in all experiments.

\subsection{Experimental Apparatus [4]}

Briefly, the main part of the apparatus is a sapphire cylindrical vessel, which can withstand pressures higher than $10 \mathrm{MPa}$. The volume of the vessel is $33.1 \mathrm{~cm}^{3}$. A stirrer was installed in the vessel to agitate the fluids and hydrate crystals inside it. Two platinum resistance thermometers (Pt100) inserted into the vessel were used to measure temperatures and check for their equality within temperature measurement uncertainty, which is estimated to be less than $0.1 \mathrm{~K}$. This temperature uncertainty estimation comes from calibration against a $25 \Omega$ reference platinum resistance thermometer. The pressure in the vessel was measured with two Druck pressure transducers (Druck, type PTX611 for pressure ranges up to (2.5 and 12) $\mathrm{MPa}$, respectively). Pressure measurement uncertainties are estimated to be less than $5 \mathrm{kPa}$, as a result of calibration against a dead weight balance (Desgranges and Huot, model 520).

\subsection{Experimental Method [4]}

The liquid water + liquid hydrocarbon + hydrate + vapor equilibrium conditions were measured with an isochoric pressure search method [2-5]. The vessel containing liquids (approximately $10 \%$ by volume of the vessel was filled with water and $10 \%$ by volume with liquid hydrocarbon) was immersed into the temperature-controlled bath, and the gas was supplied from cylinder through a pressure-regulating valve into the vessel. Note that the vessel was evacuated before the introduction of any liquid and gas. After obtaining temperature and pressure stability (far enough from the hydrate formation region), the valve in the line connecting the vessel and the cylinder was closed. Subsequently, temperature was slowly decreased to form the hydrate. Hydrate formation in the vessel was detected by pressure drop. The temperature was then increased with steps of $0.1 \mathrm{~K}$. At every temperature step, temperature was kept constant with 
sufficient time to achieve an equilibrium state in the vessel. In this way, a pressure-temperature diagram was obtained for each experimental run, from which we determined the hydrate dissociation point $[2-4,11]$. If the temperature is increased in the hydrate-forming region, hydrate crystals partially dissociate, thereby substantially increasing the pressure. If the temperature is increased outside the hydrate region, only a small increase in the pressure is observed as a result of temperature increase [2-4, 11]. Consequently, the point at which the slope of pressure-temperature data plots changes sharply is considered to be the point at which all hydrate crystals have dissociated and hence reported as the dissociation point $[2-4,11]$.

\section{RESULTS AND DISCUSSION}

All the experimental data are reported in Table 2 and are plotted in Figures 1 and 2. A semi-logarithmic scale has been used in these figures to show the data consistency, as the logarithm of hydrate dissociation pressure versus temperature has approximately linear behavior. As mentioned earlier, we first measured the hydrate dissociation conditions for the methane + isopentane + water system, for which there is sufficient experimental data in the literature $[1,6,7]$. As can

\section{TABLE 2}

Experimental dissociation data for clathrate hydrates of methane + isopentane and carbon dioxide + isopentane

\begin{tabular}{ll}
\hline$T(\mathrm{~K})$ & $P(\mathrm{MPa})$ \\
\hline \multicolumn{2}{c}{ Methane + isopentane } \\
\hline 275.5 & 2.73 \\
279.6 & 4.69 \\
283.1 & 7.46 \\
285.7 & 10.77 \\
\hline \multicolumn{2}{c}{ Carbon dioxide + isopentane } \\
\hline 273.5 & 1.18 \\
274.1 & 1.28 \\
274.6 & 1.36 \\
275.1 & 1.46 \\
275.6 & 1.55 \\
276.3 & 1.70 \\
276.8 & 1.82 \\
277.4 & 1.96 \\
278.0 & 2.12 \\
278.2 & 2.18 \\
278.9 & 2.37 \\
279.3 & 2.51 \\
279.8 & 2.68 \\
280.5 & 2.94 \\
281.1 & 3.22 \\
281.3 & 3.26 \\
281.7 & 3.43 \\
282.4 & 3.74 \\
\hline
\end{tabular}

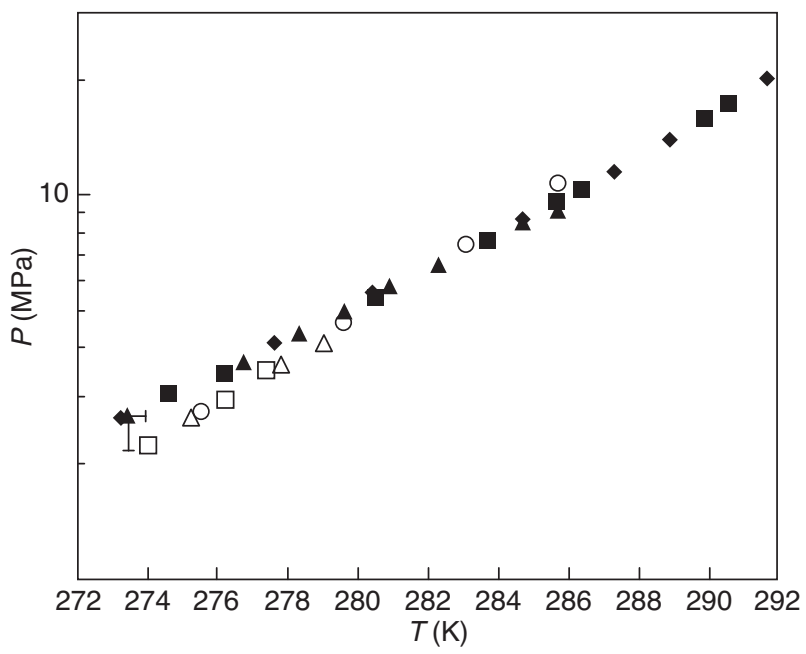

Figure 1

Experimental dissociation conditions for clathrate hydrates of methane and methane + isopentane. Symbols represent experimental data. Methane + water system: $\mathbf{\square},[8] ; \boldsymbol{\Lambda}$, [9]; $\diamond,[10]$. Methane + isopentane + water system: $\bigcirc$, this work; $\triangle$, [6]; $\square$, [7]. Pressure band: $0.5 \mathrm{MPa}$; temperature band: $0.5 \mathrm{~K}$.

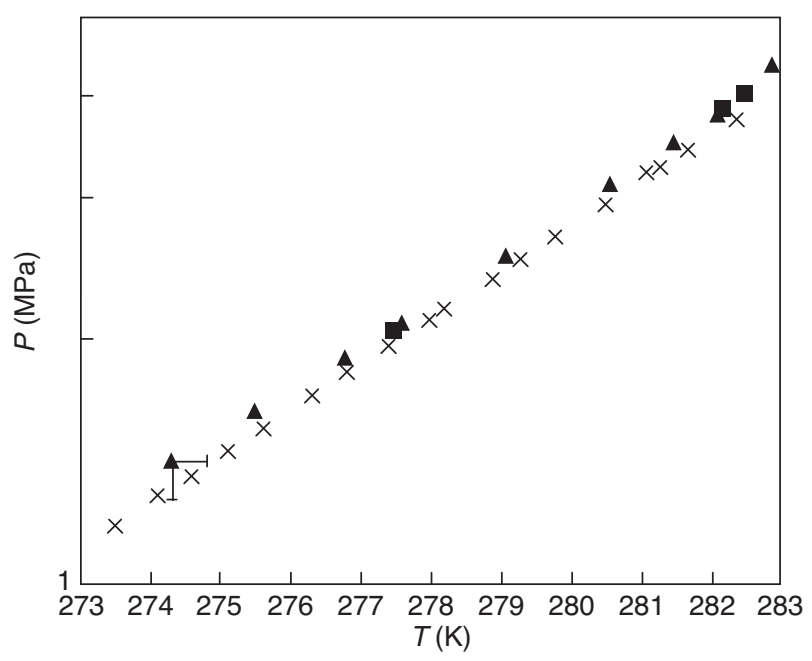

Figure 2

Experimental dissociation conditions for clathrate hydrates of carbon dioxide and carbon dioxide + isopentane. Symbols represent experimental data. Carbon dioxide + water system: $\mathbf{\square}$, [8]; $\boldsymbol{\Delta}$, [9]; Carbon dioxide + isopentane + water system: $\times$, this work. Pressure band: $0.15 \mathrm{MPa}$; temperature band: $0.5 \mathrm{~K}$.

be observed in Figure 1, the experimental data measured in this work for the latter system are in good agreement with the experimental data reported in the literature $[1,6,7]$ demonstrating the reliability of the experimental method [2-5] used in this work. In both figures, we have shown some selected experimental data from the literature for the methane + water $[8-10]$ and carbon dioxide + water systems $[8,9]$, respectively, 
to study the hydrate promotion effects of the isopentane. It should be mentioned that hydrate promotion effects means shifting dissociation conditions of methane or carbon dioxide simple hydrates due to the presence of isopentane to low pressures/high temperatures. As can be seen in Figure 1, the presence of isopentane increases the hydrate dissociation temperature of the methane + water system by approximately $0.5 \mathrm{~K}$ at given pressures for temperatures up to $278 \mathrm{~K}$. However, this value depends on pressure and can vary for this system. In this figure, the decrease in hydrate dissociation pressure of the methane + water system due to the presence of isopentane in the system is approximately $0.5 \mathrm{MPa}$, which is function of temperature. In Figure 2, it can be observed that the presence of isopentane can reduce the hydrate dissociation pressure of the carbon dioxide + water system by approximately $0.15 \mathrm{MPa}$ at given temperatures and in other words, it can increase the hydrate dissociation temperature by approximately $0.5 \mathrm{~K}$ at given pressures. In both figures, the slope of the logarithm of hydrate dissociation pressure versus temperature due to the presence of isopentane in the systems changes indicating a likely change in the clathrate hydrate structure [1]. As it has already been confirmed that the methane + isopentane clathrate hydrates form $s H$, we expect that the carbon dioxide + isopentane clathrate hydrates likely form $s H$. However, a final proof for the stable hydrate structure and compositions of isopentane + carbon dioxide clathrate hydrates require direct measurements by suitable physical techniques (e.g., NMR, X-ray, or Raman spectroscopy).

\section{CONCLUSIONS}

We reported experimental dissociation data for clathrate hydrates of isopentane + carbon dioxide and isopentane + methane in the temperature ranges of (273.5-282.4) and (275.5-285.7), respectively. An isochoric pressure-search method [2-5] was used to perform all the measurements. The measurements were first performed for the methane + isopentane + water system, for which there is sufficient experimental data in the literature $[1,6,7]$. The comparisons between the experimental data generated in this work and the literature data $[1,6,7]$ showed acceptable agreement confirming the reliability of the isochoric pressure-search method [2-5] used in this work. We then reported experimental dissociation data for clathrate hydrates of isopentane with carbon dioxide as potential help gas for which there is no information in the literature. The comparison of the hydrate dissociation data for the aforementioned ternary systems with the experimental data reported in the literature for the corresponding binary systems of methane + water [8-10] and carbon dioxide + water $[8,9]$ showed that isopentane cannot reduce hydrate dissociation pressures very considerably.

\section{ACKNOWLEDGMENT}

The financial support of Agence Nationale de la Recherche (ANR) is gratefully acknowledged.

\section{REFERENCES}

1 Sloan E.D., Koh C.A. (2008) Clathrate Hydrates of Natural Gases, Third Edition, CRC Press, Taylor \& Francis Group, Boca Raton.

2 Mohammadi A.H., Afzal W., Richon D. (2008) Gas Hydrates of Methane, Ethane, Propane and Carbon Dioxide in the Presence of Single $\mathrm{NaCl}, \mathrm{KCl}$ and $\mathrm{CaCl}_{2}$ Aqueous Solutions: Experimental Measurements and Predictions of Dissociation Conditions, J. Chem. Thermodyn. 40, 1693-1697.

3 Mohammadi A.H., Kraouti I., Richon D. (2009) Methane hydrate phase equilibrium in the presence of $\mathrm{NaBr}, \mathrm{KBr}, \mathrm{CaBr}_{2}$, $\mathrm{K}_{2} \mathrm{CO}_{3}$, and $\mathrm{MgCl}_{2}$ aqueous solutions: Experimental measurements and predictions of dissociation conditions, J. Chem. Thermodyn. 41, 779-782.

4 Mohammadi A.H., Richon D. (2009) Equilibrium Data of Carbonyl Sulfide and Hydrogen Sulfide Clathrate Hydrates, J. Chem. Eng. Data 54, 2338-2340.

5 Tohidi B., Burgass R.W., Danesh A., Østergaard K.K., Todd A.C. (2000) Improving the Accuracy of Gas Hydrate Dissociation Point Measurements, Ann. N.Y. Acad. Sci. 912, 924-931.

6 Mehta A.P., Sloan E.D. (1993) Structure H hydrate phase equilibria of methane + liquid hydrocarbon mixtures, J. Chem. Eng. Data 38, 580-582 (Quoted in [1]).

7 Hütz U., Englezos P. (1995) Measurement of Structure H Hydrate Phase Equilibrium and Effect of Electrolytes, Proc. 7th International Conference on Fluid Properties and Phase Equilibria for Chemical Process Design, (Quoted in [1]).

8 Mohammadi A.H., Anderson R., Tohidi B. (2005) Carbon Monoxide Clathrate Hydrates: Equilibrium Data and Thermodynamic Modeling, AIChE J. 51, 2825-2833, (Quoted in [1]).

9 Adisasmito S., Frank R.J., Sloan E.D. (1991) Hydrates of carbon dioxide and methane mixtures, J. Chem. Eng. Data 36, 68-71, (Quoted in [1]).

10 Jhaveri J., Robinson D.B. (1965) Hydrates in the methanenitrogen system, Can. J. Chem. Eng. 43, 75-78, (Quoted in [1]).

11 Ohmura R., Takeya S., Uchida T., Ebinuma T. (2004) Clathrate Hydrate Formed with Methane and 2-Propanol: Confirmation of Structure II Hydrate Formation, Ind. Eng. Chem. Res. 43, 4964-4966.

Final manuscript received in November 2009 Published online in October 2010

Copyright (C) 2010 IFP Energies nouvelles

Permission to make digital or hard copies of part or all of this work for personal or classroom use is granted without fee provided that copies are not made or distributed for profit or commercial advantage and that copies bear this notice and the full citation on the first page. Copyrights for components of this work owned by others than IFP Energies nouvelles must be honored. Abstracting with credit is permitted. To copy otherwise, to republish, to post on servers, or to redistribute to lists, requires prior specific permission and/or a fee: Request permission from Documentation, IFP Energies nouvelles, fax.+331475270 78, or revueogst@ifpenergiesnouvelles.fr. 